\title{
Psychostimulants As Cognitive Enhancers in Adolescents: More Risk than Reward?
}

\author{
Kimberly R. Urban ${ }^{1 *}$ and Wen-Jun Gao ${ }^{2 *}$ \\ ${ }^{1}$ Department of General Anesthesia, Division of Stress Neurobiology, Children's Hospital of Philadelphia, Philadelphia, PA, \\ United States, ${ }^{2}$ Department of Neurobiology and Anatomy, Drexel University College of Medicine, Philadelphia, PA, \\ United States
}

Methylphenidate and other psychostimulants, originally developed to treat attention deficit-hyperactivity disorder, are increasingly abused by healthy adolescents and adults seeking an advantage in scholastic performance and work productivity. However, how these drugs may affect cognitive performance, especially in the young brain, remains unclear. Here, we review recent literature and emphasize the risks of abuse of psychostimulants in healthy adolescents and young adults. We conclude that while the desire

OPEN ACCESS

Edited by:

Meichun Mohler-Kuo, University of Zurich, Switzerland

Reviewed by: Costin Roventa, Prof. Dr. Alexandru Obregia Psychiatry Hospital, Romania Andreas Guenter Franke, Neubrandenburg University of Applied Sciences, Germany

*Correspondence: Kimberly R. Urban willow783@hotmail.com; Wen-Jun Gao wg38@drexel.edu

Specialty section:

This article was submitted to Public Mental Health,

a section of the journal

Frontiers in Public Health

Received: 16 June 2017 Accepted: 12 September 2017 Published: 26 September 2017

Citation:

Urban KR and Gao W-J (2017)

Psychostimulants As Cognitive

Enhancers in Adolescents:

More Risk than Reward?

Front. Public Health 5:260. doi: 10.3389/fpubh.2017.00260 for cognitive enhancement, particularly with rising costs of education and increasingly competitive nature of scholarship programs, is unlikely to diminish in the near future, it is crucial for the scientific community to thoroughly examine the efficacy and safety of these stimulants in healthy populations across development. The current dearth of knowledge on the dose-response curve, metabolism, and cognitive outcomes in adolescents following methylphenidate or other psychostimulant exposure may be perpetuating a perception of these drugs as "safe" when that might not be true for developing brains.

Keywords: methylphenidate, psychostimulant, adolescence, young adult, learning drugs, drug abuse, psychiatry

Attention deficit-hyperactivity disorder (ADHD) is one of the most commonly diagnosed childhood psychiatric disorders, affecting 5\% (1) to $11 \%$ (2) of children aged 4-17 years old. Diagnosis of ADHD has increased in the United States during the past two decades $(3,4)$. The exact cause of this increase is unknown, but may be attributable to better diagnostic tests, increasing awareness of ADHD, or even perhaps conflicts of interest (doctors appeasing concerned parents). Diagnosis is largely subjective, and stringency of adherence to the DSM-V criteria varies: many children are taken to a primary-care physician on the advice of a teacher, and given methylphenidate (MPH) or amphetamine (AMPH) as a first-line treatment, often without rigorous psychiatric testing (5). ADHD is thought to arise from a deficit of the neurotransmitters dopamine (DA) and norepinephrine (NE) in the prefrontal cortex (PFC), which leads to impairments in executive function, causing symptoms of impulsivity, locomotor hyperactivity, and impairments in judgment and social behavior, and can lead to devastating impairments in scholastic and job performance and deteriorating social relationships if left untreated $(6,7)$. Functional magnetic resonance imaging (fMRI) and positron emission tomography (PET) imaging taken from individuals diagnosed with ADHD have shown reductions in blood flow in the PFC $(8,9)$. Proper function of PFC relies on the concentrations of the neurotransmitters DA and NE; these neurotransmitters exert control over executive function in an inverted-U curve manner: both insufficient and excessive levels result in impairments in PFC functions $(10,11)$. The PFC undergoes extensive synaptic pruning throughout puberty and into early adulthood. This delayed maturation may impart particular vulnerability of the adolescent brain to perturbations such as drug abuse, injury, and stress (12). In fact, many psychiatric illnesses, including 
$\mathrm{ADHD}$, that manifest with impairments in executive function, are largely diagnosed and treated in juveniles and adolescents (13). ADHD and stress-related psychiatric disorders include impairments in working memory as a common symptom, further implicating PFC impairment in their pathology.

Psychostimulants are currently the first-line treatment for ADHD in both children and adults; of these, MPH is the most widely prescribed $(14,15)$. MPH exerts its therapeutic effect by blocking the function of the DA transporter (DAT) and norepinephrine transporter [NET, thereby increasing the bioavailability of the neurotransmitters and correcting the deficit thought to cause ADHD (16-18)]. The first stimulant approved for ADHD treatment AMPH (Adderall@) blocks reuptake but also increases vesicular release of DA; the effect on DA release is the main action at low doses (19). There is a large body of research supporting the conclusion that psychostimulant treatment reduces symptoms of ADHD, particularly hyperactivity (20). However, how other psychostimulants may affect cognitive performance is less clear, due to varying dosages, varying ages of subjects, and the fact that many tests of executive function contain non-executive domains on which improvement is noted after psychostimulant treatment. For example, $\mathrm{MPH}$ is effective at improving performance on a simple reaction time, task-switching paradigm, focused attention, word-matching, and go/no-go tasks in children with diagnosis of $\mathrm{ADHD}$, but not spatial working memory (SWM), pattern recognition, or divided attention tasks (21-30). Regardless, stimulant medications seem to improve cognitive function in an inverted$\mathrm{U}$ curve manner, with lower doses improving and higher doses impairing various aspects of cognition (17).

Animal studies have been used to examine safety and efficacy of MPH and similar psychostimulants such as AMPH for decades; rats possess the same neurotransmitter systems and pathways as humans and have a more primitive, but similar, PFC. Studies of stimulant actions in rodents have shown varied, often contradictory effects, due to inconsistencies in dosing. For example, MPH caused hyperlocomotion and chasing in a paired open-field task, reduce learning retention, alter gene expression, and produce stereotypies; however, these studies used high doses of MPH (31-37). Low-dose MPH has been shown to improve performance on sustained attention, signal detection, and attentional set-shifting (38-40). For a more thorough historical review of rodent MPH studies, see Ref. (41). Adult rodent studies and studies on adult human volunteers suggested that psychostimulant improvement of cognition was not "paradoxical effect" observable only in ADHD and models of ADHD, but also presented in healthy individuals. Further recent studies corroborated the theory that low-dose psychostimulant treatment (doses that correspond to those given to ADHD patients) appears to enhance prefrontal cortical-dependent functions and cognitive performance in healthy individuals in a similar manner to ADHD patients (42-45). This led to consideration of MPH as a nootropic, or cognitive-enhancing, drug.

Today, MPH is increasingly abused by adolescents and adults seeking an advantage in scholastic performance and work productivity. It is used to aid memory when studying for exams and to improve focus and wakefulness $(46,47)$. MPH and other similar substances are also highly abused by members of the military to improve attention in high-stress situations and combat the effects of sleep deprivation (48). Prevalence reports range from 2 to $20 \%$ of respondents admitting to cognitive enhancement (47, 49-51). There is extreme controversy regarding cognitive enhancement, with physicians and the public questioning safety and morality of the artificial augmentation of cognition (52-55) and even doubts about the true prevalence of misuse (56). Despite the rising abuse of MPH among adolescents and young adults, the basis for its safety and efficacy as a nootropic arises from studies performed on adult rodents and human volunteers; there is little information about the potential adverse behavioral and cognitive effects of stimulant treatment in normal adolescents. Recent precious little research has been conducted using adolescent or juvenile rodents until the last 5 years. These studies have revealed strikingly different effects than adult rodent studies. For example, adolescent MPH exposure was found to reduce social play, impair pattern learning and reversal learning, increase locomotor hyperactivity, and response to cocaine, sometimes lasting into adulthood (57-60). Early exposure to MPH has also been shown to result in increased anxiety lasting into adulthood and alter circadian rhythms (61-65). However, many of the recent studies on adolescent rats have not been consistent in their dosing regimens, leading to concern as to the therapeutic relevance of the results. A therapeutically relevant dose range that results in peak blood plasma levels equivalent to those measured in successfully treated patients $(8-40 \mathrm{ng} / \mathrm{dL})$ has been established for adult rats at $0.5-1 \mathrm{mg} / \mathrm{kg}$ injected intraperitoneally, but the dose-response range has not been systematically examined for adolescent rats (18). We recently reported that a single dose of $1 \mathrm{mg} / \mathrm{kg}$ intraperitoneal given at 17-25 postnatal days in the rat resulted in significant depression of neuronal activity and synaptic transmission in the layer $\mathrm{V}$ pyramidal neurons of the PFC. This same dose resulted in the expected increase of activity in those same neurons in adult rats (66). These results suggest that there is an age-dependent effect of MPH in the PFC, and that the juvenile brain may be hypersensitive to the effects of psychostimulants, and even a low dose may push the healthy developing brain into a hyperdopaminergic and hyperadrenergic state. We further examined the effects of a single $1 \mathrm{mg} / \mathrm{kg}$ dose of MPH on glutamate receptors and plasticity in the juvenile rat, and reported that MPH selectively reduced levels of NR2B-containing NMDA receptors, and abolished short-term facilitation while enhancing long-term potentiation (LTP) and decreasing long-term depression (LTD) (67). Excessive DA levels can lead to reduced expression of NR2B-containing NMDA receptors via activation of the glycogen synthase kinase (GSK-3 $\beta$ ) pathway, disrupting $\beta$-catenin association with NR2B and allowing ubiquitination (68).

Despite its widespread misuse and ready availability, MPH is not the only psychostimulant or catecholaminergic agent considered for its utility as a cognitive enhancer. Amphetamine has been shown to improve consolidation and recall. However, it is associated with a variety of neurotoxic negative effects, including synaptic terminal degradation and neuronal chromatolysis in cortex and striatum, and permanent loss of DA uptake sites in striatum and nucleus accumbens (69-74). Furthermore, AMPH can induce a schizophrenia-like psychosis marked by hallucinations, paranoia, panic, and hyperactivity (75-77). AMPH produces more rapid 
sensitization than MPH and induces a robust subjective "high" through its actions on serotonin, making it more addictive than $\mathrm{MPH}$ and less popularly used as a nootropic (78). In the PFC, both NE and DA are taken up by the NET due to limited expression of the DAT (79) and the relatively high affinity of DA for NET as compared with DAT $(80,81)$. Therefore, the transporter selectivity of a compound may influence its utility as a cognitive enhancer and its abuse potential. AHN 2-005, a DAT-selective compound, significantly increased extracellular levels of both NE and DA in the PFC at a cognition-enhancing dose that lacked locomotor activating effects, similar to $\mathrm{MPH}$ (82). However, AHN 2-005 produced a larger increase in extracellular DA in the nucleus accumbens than PFC. Although MPH selectively affected DA and NE levels in PFC $(18,82)$, it has yet to be considered a cognitive enhancer, largely due to its unavailability in the market.

Another important ADHD medication is atomoxetine (Strattera $\odot$ ), which is a non-stimulant and is also rarely considered a cognitive enhancer despite its nootropic and abuse potential. While there are far fewer peer-reviewed studies of atomoxetine as a cognitive enhancer, Internet searches reveal multiple forums and discussions of its efficacy and safety among individuals taking this drug illicitly. Atomoxetine selectively inhibits NET, with no appreciable actions on the DAT or other systems associated with abuse potential (83-85). Therefore, atomoxetine lacks the central nervous system stimulant effects of MPH and AMPH, reducing the risk of cardiovascular events (86). However, atomoxetine has been shown to bind to serotonin transporters, which may blunt its nootropic effects, as extrasynaptic serotonin can impair episodic memory and recall and may be anxiogenic (87). See Table 1 for a summary of relevant psychostimulants and ADHD medications considered for cognitive enhancing usage in healthy adolescents and young adults.

Despite these studies, it is still unclear how NET and DAT individually influence catecholamine balance in PFC; however, at least some evidence suggests that both are important (88). Furthermore, how low doses of psychostimulants preferentially target catecholamines in PFC without affecting other brain regions is unknown, and it may be unfeasible to elucidate potential mechanisms in vivo due to the common ligands and overlapping functions of the NET and DAT, as well as the fact that most compounds have at least some reactivity with both. How can NET control reuptake of both catecholamines in PFC if it is dominant to DAT? Furthermore, it is important to elucidate the contributions of DAT and NET to the uptake of NE and DA across development. Specifically, is PFC DAT expression already low compared to NET at birth, or does the expression of DAT progressively decrease during development? Since MPH induces opposite effects on neuronal activity, synaptic transmission, and plasticity in the juvenile versus adult animal PFC in a clinically relevant dose for adult $(66,89)$, it is important to explore the developmental expression and function of NET and DAT in the PFC.

What do our results and the results of similar studies mean for the adolescent taking MPH or similar psychostimulants? How does this differ from the consequences for an adult taking psychostimulants? MPH and other psychostimulants are thought to exert their therapeutic effect by raising levels of DA and NE specifically in the PFC; this leads to increases in neuronal activity and enhanced prefrontal cortical top-down control of executive functions (17). However, DA and NE exert an "inverted-U” curve of effects in the PFC: too little and the PFC is not able to function, resulting in impulsiveness, inattentiveness, locomotor hyperactivity, and poor decision-making, too much and the signal-to-noise ratio of neuronal firing is lost, resulting in scattered attention, stereotypic movements, hyperactivity, and impulsiveness (10, 90). In individuals with $\mathrm{ADHD}$, and low levels of DA and NE, psychostimulants would raise the levels into the optimal range, and in healthy adults, it appears that low-dose psychostimulants may further optimize catecholamine levels and provide improvements in executive function (91-98). Thus, psychostimulants given at low doses similar to those used to treat ADHD may indeed provide an effective and largely safe cognitive enhancement, as the PFC of adults has finished maturing $(11,12,99)$.

However, in the adolescent brain, levels of DA and NE are naturally higher, as the PFC development is ongoing and synaptic pruning has not been completed; thus, adding psychostimulants likely pushes the levels of DA and NE beyond the optimal range and into excessive levels (12). This is consistent with impairments in pattern learning and object-memory, reduced pyramidal neuron activity, and reduced NR2B-containing NMDA receptor levels seen in our studies $(66,67)$. The precise function of LTP in the PFC has not been elucidated; however, it has been hypothesized that if persistent firing and short-term facilitation are a measure of working memory, then LTP might be a neuronal correlate of sustained attention and memory consolidation/ learning. If this is the case, we can predict that psychostimulant

TABLE 1 | Summary of psychostimulants and compounds affecting catecholamine reuptake considered for cognitive enhancement abilities.

\begin{tabular}{|c|c|c|c|c|}
\hline Chemical & Brand name(s) & $\begin{array}{l}\text { Mechanism of } \\
\text { action }\end{array}$ & $\begin{array}{l}\text { Neurotransmitters systems } \\
\text { affected }\end{array}$ & Abuse potential \\
\hline Methylphenidate & $\begin{array}{l}\text { Concerta@ and } \\
\text { Ritalin@ }\end{array}$ & $\begin{array}{l}\text { NET and DAT } \\
\text { inhibitor }\end{array}$ & Norepinephrine and dopamine & $\begin{array}{l}\text { Moderate. Does not produce addiction, but is commonly sold off-label } \\
\text { and taken by adolescents and young adults for nootropic effects }\end{array}$ \\
\hline Amphetamine & $\begin{array}{l}\text { Adderall@ and } \\
\text { Adzenys XR-ODT }\end{array}$ & $\begin{array}{l}\text { NET, DAT, and SET } \\
\text { inhibitor }\end{array}$ & $\begin{array}{l}\text { Norepinephrine, dopamine, and } \\
\text { serotonin }\end{array}$ & $\begin{array}{l}\text { High. Addictive, produces subjective "high." Commonly abused and } \\
\text { readily available }\end{array}$ \\
\hline Atomoxetine & Strattera@ & NET inhibitor & $\begin{array}{l}\text { Norepinephrine (potentially } \\
\text { serotonin) }\end{array}$ & $\begin{array}{l}\text { Low. Does not produce addiction, no stimulant actions, but is readily } \\
\text { available }\end{array}$ \\
\hline AHN 2-005 & N/A & DAT inhibitor & Dopamine & Negligible. Not commercially available \\
\hline
\end{tabular}

DAT, dopamine transporter; NET, norepinephrine transporter; SET, serotonin transporter. 
abuse by adolescents and juveniles could result in impairments in working memory and behavioral flexibility, but enhanced sustained attention. Thus, in a scholastic setting, adolescents taking MPH off-label or in abusing the drug may appear to be improving; however, rigid testing of working memory and cognitive flexibility might reveal impairments that could negatively impact their lives. For example, the ability to quickly redirect attention is critical for sports and driving: on the road, one must be able to notice approaching cars and quickly determine the optimal response, shifting gaze from the road to one's dashboard, and back again. In a work setting, especially in jobs that require management of subordinates or teamwork, the roles of individuals may change, and one must be able to evaluate quickly one's performance. Inability to approach problems from different paths could lead to poor performance at work, leading to reduced pay or termination of employment. Finally, behavioral rigidity could potentially raise the risk of drug addiction, as inability to terminate behaviors associated with the taking of drugs is a common obstacle to recovery and impaired flexibility has been shown in multiple addiction phenotypes in humans (100-102).

While it is currently unclear if the impacts of low-dose $\mathrm{MPH}$ on the juvenile PFC are permanent, our research suggests that recovery depends on dose; neuronal activity and synaptic transmission recovered to control levels within 1 week following $1 \mathrm{mg} / \mathrm{kg}$ but did not recover even 10 weeks after 3 or $9 \mathrm{mg} /$ $\mathrm{kg}$ treatment in the rat (66). Individuals abusing stimulants on college and high-school campuses are often exposing themselves

\section{REFERENCES}

1. Poulin C. From attention-deficit/hyperactivity disorder to medical stimulant use to the diversion of prescribed stimulants to non-medical stimulant use: connecting the dots. Addiction (2007) 102:740-51. doi:10.1111/j.1360-0443. 2007.01758.x

2. Visser SN, Danielson ML, Bitsko RH, Holbrook JR, Kogan MD, Ghandour RM, et al. Trends in the parent-report of health care providerdiagnosed and medicated attention-deficit/hyperactivity disorder: United States, 2003-2011. J Am Acad Child Adolesc Psychiatry (2014) 53(34-46):e32. doi:10.1016/j.jaac.2013.09.001

3. Zito JM, Safer DJ, dosReis S, Gardner JF, Boles M, Lynch F. Trends in the prescribing of psychotropic medications to preschoolers. JAMA (2000) 283: 1025-30. doi:10.1001/jama.283.8.1025

4. Fairman KA, Peckham AM, Sclar DA. Diagnosis and treatment of ADHD in the United States. J Atten Disord (2017):1087054716688534. doi:10.1177/ 1087054716688534

5. Smith BL. Inappropriate prescribing. Monitor on Psychology. Washington, DC: American Psychological Association (2012). 43(6):36.

6. Arnsten AF. Fundamentals of attention-deficit/hyperactivity disorder: circuits and pathways. J Clin Psychiatry (2006) 67(Suppl 8):7-12.

7. Arnsten AF. Toward a new understanding of attention-deficit hyperactivity disorder pathophysiology: an important role for prefrontal cortex dysfunction. CNS Drugs (2009) 23:8. doi:10.2165/00023210-20092300000005

8. Epstein JN, DelBello MP, Adler CM, Altaye M, Kramer M, Mills NP, et al. Adolescents with ADHD demonstrate differential developmental patterns of functional activation in right prefrontal cortex compared to non-ADHD controls. Neuropediatrics (2009) 40:1-5. doi:10.1055/s-0029-1220686

9. Kucyi A, Hove MJ, Biederman J, Van Dijk KR, Valera EM. Disrupted functional connectivity of cerebellar default network areas in attention-deficit/ hyperactivity disorder. Hum Brain Mapp (2015) 36:3373-86. doi:10.1002/ hbm. 22850 to much higher doses than are typically clinically prescribed, and doing so without the benefit of building tolerance; thus, they may be particularly vulnerable to long-lasting alterations in prefrontal cortical function. The desire for cognitive enhancement, particularly with rising costs of education and increasingly competitive nature of scholarship programs, is unlikely to diminish in the near future; therefore, it is crucial for the scientific community to thoroughly examine the efficacy and safety of each candidate substance. The current dearth of knowledge on the dose-response curve, metabolism, and cognitive outcomes in juveniles and adolescents following MPH or other psychostimulant exposure may be perpetuating a perception of these drugs as "safe" for any age when that might not be true. Until the research is completed to give us a more thorough understanding of the drugs' actions in the developing PFC, off-label use of psychostimulants and nootropics may present more risk than reward for adolescents.

\section{AUTHOR CONTRIBUTIONS}

All authors listed have made a substantial, direct, and intellectual contribution to the work and approved it for publication.

\section{FUNDING}

This study is supported by the NIH (grant number R01MH085666 to W-JG).
10. Arnsten AF. Catecholamine regulation of the prefrontal cortex. J Psychopharmacol (1997) 11:151-62. doi:10.1177/026988119701100208

11. Arnsten AF. Catecholamine and second messenger influences on prefrontal cortical networks of "representational knowledge": a rational bridge between genetics and the symptoms of mental illness. Cereb Cortex (2007) 17(Suppl 1): i6-15. doi:10.1093/cercor/bhm033

12. Arnsten AF. Development of the cerebral cortex: XIV. Stress impairs prefrontal cortical function. J Am Acad Child Adolesc Psychiatry (1999) 38:220-2. doi:10.1097/00004583-199902000-00024

13. Arnsten AF, Shansky RM. Adolescence: vulnerable period for stress-induced prefrontal cortical function? Introduction to part IV. Ann N Y Acad Sci (2004) 1021:143-7. doi:10.1196/annals.1308.017

14. Challman TD, Lipsky JJ. Methylphenidate: its pharmacology and uses. Mayo Clin Proc (2000) 75:711-21. doi:10.4065/75.7.711

15. Wigal SB. Efficacy and safety limitations of attention-deficit hyperactivity disorder pharmacotherapy in children and adults. CNS Drugs (2009) 23(Suppl 1):21-31. doi:10.2165/00023210-200923000-00004

16. Kuczenski R, Segal DS. Stimulant actions in rodents: implications for attention-deficit/hyperactivity disorder treatment and potential substance abuse. Biol Psychiatry (2005) 57:1391-6. doi:10.1016/j.biopsych. 2004.12.036

17. Arnsten AF. Stimulants: therapeutic actions in ADHD. Neuropsychopharma$\operatorname{cology}$ (2006) 31:2376-83. doi:10.1038/sj.npp.1301164

18. Berridge CW, Devilbiss DM, Andrzejewski ME, Arnsten AF, Kelley AE, Schmeichel B, et al. Methylphenidate preferentially increases catecholamine neurotransmission within the prefrontal cortex at low doses that enhance cognitive function. Biol Psychiatry (2006) 60:1111-20. doi:10.1016/j.biopsych. 2006.04.022

19. Calipari ES, Ferris MJ. Amphetamine mechanisms and actions at the dopamine terminal revisited. J Neurosci (2013) 33:8923-5. doi:10.1523/JNEUROSCI. 1033-13.2013

20. Group MC. National Institute of Mental Health Multimodal Treatment Study of ADHD follow-up: 24-month outcomes of treatment strategies 
for attention-deficit/hyperactivity disorder. Pediatrics (2004) 113:754-61. doi:10.1542/peds.113.4.754

21. Trommer BL, Hoeppner JA, Zecker SG. The go-no go test in attention deficit disorder is sensitive to methylphenidate. JChild Neurol (1991) 6(Suppl): S128-31. doi:10.1177/0883073891006001S13

22. Malone MA, Swanson JM. Effects of methylphenidate on impulsive responding in children with attention-deficit hyperactivity disorder. J Child Neurol (1993) 8:157-63. doi:10.1177/088307389300800209

23. de Sonneville LM, Njiokiktjien C, Bos H. Methylphenidate and information processing. Part 1: differentiation between responders and nonresponders. Part 2: efficacy in responders. JClin Exp Neuropsychol (1994) 16:877-97. doi:10.1080/01688639408402700

24. Cepeda NJ, Cepeda ML, Kramer AF. Task switching and attention deficit hyperactivity disorder. J Abnorm Child Psychol (2000) 28:213-26. doi:10.1023/ A:1005143419092

25. Mehta MA, Owen AM, Sahakian BJ, Mavaddat N, Pickard JD, Robbins TW. Methylphenidate enhances working memory by modulating discrete frontal and parietal lobe regions in the human brain. J Neurosci (2000) 20:RC65.

26. Tannock R, Martinussen R, Frijters J. Naming speed performance and stimulant effects indicate effortful, semantic processing deficits in attention-deficit/ hyperactivity disorder. J Abnorm Child Psychol (2000) 28:237-52. doi:10.1023/ A:1005192220001

27. Scheres A, Oosterlaan J, Swanson J, Morein-Zamir S, Meiran N, Schut H, et al. The effect of methylphenidate on three forms of response inhibition in boys with AD/HD. J Abnorm Child Psychol (2003) 31:105-20. doi:10.102 3/A:1021729501230

28. Konrad K, Gunther T, Hanisch C, Herpertz-Dahlmann B. Differential effects of methylphenidate on attentional functions in children with attention-deficit/ hyperactivity disorder. J Am Acad Child Adolesc Psychiatry (2004) 43:191-8. doi:10.1097/00004583-200402000-00015

29. Cepeda C, Levine MS. Where do you think you are going? The NMDA-D1 receptor trap. Sci STKE (2006) 2006:e20. doi:10.1126/stke.3332006pe20

30. Rhodes SM, Coghill DR, Matthews K. Acute neurospychological effects of methylphenidate in stimulant drug-naive boys with ADHD II--broader executive and non-executive domains. J Child Psychol Psychiatry (2006) 47: 1184-94. doi:10.1111/j.1469-7610.2006.01633.x

31. Arakawa O. Effects of methamphetamine and methylphenidate on single and paired rat open-field behaviors. Physiol Behav (1994) 55:441-6. doi:10.1016/ 0031-9384(94)90098-1

32. Gaytan O, Ghelani D, Martin S, Swann A, Dafny N. Dose response characteristics of methylphenidate on different indices of rats' locomotor activity at the beginning of the dark cycle. Brain Res (1996) 727:13-21. doi:10.1016/ 0006-8993(96)00296-X

33. Gaytan O, al-Rahim S, Swann A, Dafny N. Sensitization to locomotor effects of methylphenidate in the rat. Life Sci (1997) 61:L101-7. doi:10.1016/ S0024-3205(97)00598-5

34. Brandon CL, Marinelli M, Baker LK, White FJ. Enhanced reactivity and vulnerability to cocaine following methylphenidate treatment in adolescent rats. Neuropsychopharmacology (2001) 25:651-61. doi:10.1016/ S0893-133X(01)00281-0

35. Andersen SL, Arvanitogiannis A, Pliakas AM, LeBlanc C, Carlezon WA Jr. Altered responsiveness to cocaine in rats exposed to methylphenidate during development. Nat Neurosci (2002) 5:13-4. doi:10.1038/nn777

36. Brandon CL, Marinelli M, White FJ. Adolescent exposure to methylphenidate alters the activity of rat midbrain dopamine neurons. Biol Psychiatry (2003) 54:1338-44. doi:10.1016/S0006-3223(03)00787-X

37. Adriani W, Leo D, Guarino M, Natoli A, Di Consiglio E, De Angelis G, et al. Short-term effects of adolescent methylphenidate exposure on brain striatal gene expression and sexual/endocrine parameters in male rats. Ann N Y Acad Sci (2006) 1074:52-73. doi:10.1196/annals.1369.005

38. Berridge CW, Shumsky JS, Andrzejewski ME, McGaughy JA, Spencer RC, Devilbiss DM, et al. Differential sensitivity to psychostimulants across prefrontal cognitive tasks: differential involvement of noradrenergic alpha(1)and alpha(2)-receptors. Biol Psychiatry (2012) 71:467-73. doi:10.1016/ j.biopsych.2011.07.022

39. Bhattacharya SE, Shumsky JS, Waterhouse BD. Attention enhancing effects of methylphenidate are age-dependent. Exp Gerontol (2015) 61:1-7. doi:10.1016/ j.exger.2014.11.006
40. Navarra RL, Clark BD, Gargiulo AT, Waterhouse BD. Methylphenidate enhances early-stage sensory processing and rodent performance of a visual signal detection task. Neuropsychopharmacology (2017). doi:10.1038/ npp. 2016.267

41. Urban KR, Gao WJ. Evolution of the study of methylphenidate and its actions on the adult versus juvenile brain. J Atten Disord (2015) 19:603-19. doi:10.1177/1087054712455504

42. Askenasy EPT, Yang PB, Dafny N. Methylphenidate (ritalin): behavioral studies in the rat. Int J Neurosci (2007) 117:757-94. doi:10.1080/00207450600910176

43. Dow-Edwards DL, Weedon JC, Hellmann E. Methylphenidate improves performance on the radial arm maze in periadolescent rats. Neurotoxicol Teratol (2008) 30:419-27. doi:10.1016/j.ntt.2008.04.001

44. Agay N, Yechiam E, Carmel Z, Levkovitz Y. Non-specific effects of methylphenidate (ritalin) on cognitive ability and decision-making of ADHD and healthy adults. Psychopharmacology (Berl) (2010) 210:511-9. doi:10.1007/ s00213-010-1853-4

45. Linssen AM, Vuurman EF, Sambeth A, Riedel WJ. Methylphenidate produces selective enhancement of declarative memory consolidation in healthy volunteers. Psychopharmacology (Berl) (2012) 221:611-9. doi:10.1007/ s00213-011-2605-9

46. Goodman R. Cognitive enhancement, cheating, and accomplishment. Kennedy Inst Ethics J (2010) 20:145-60. doi:10.1353/ken.0.0309

47. Franke AG, Bonertz C, Christmann M, Huss M, Fellgiebel A, Hildt E, et al. Non-medical use of prescription stimulants and illicit use of stimulants for cognitive enhancement in pupils and students in Germany. Pharmacopsychiatry (2011) 44:60-6. doi:10.1055/s-0030-1268417

48. Sahakian BJ, Bruhl AB, Cook J, Killikelly C, Savulich G, Piercy T, et al. The impact of neuroscience on society: cognitive enhancement in neuropsychiatric disorders and in healthy people. Philos Trans R Soc Lond B Biol Sci (2015) 370:20140214. doi:10.1098/rstb.2014.0214

49. Liakoni E, Schaub MP, Maier LJ, Glauser GV, Liechti ME. The use of prescription drugs, recreational drugs, and "soft enhancers" for cognitive enhancement among Swiss secondary school students. PLoS One (2015) 10:e0141289. doi:10.1371/journal.pone.0141289

50. Schelle KJ, Olthof BM, Reintjes W, Bundt C, Gusman-Vermeer J, van Mil AC. A survey of substance use for cognitive enhancement by university students in the Netherlands. Front Syst Neurosci (2015) 9:10. doi:10.3389/fnsys.2015.00010

51. Dietz P, Soyka M, Franke AG. Pharmacological neuroenhancement in the field of economics-poll results from an online survey. Front Psychol (2016) 7:520. doi:10.3389/fpsyg.2016.00520

52. Butcher J. Cognitive enhancement raises ethical concerns. Academics urge pre-emptive debate on neurotechnologies. Lancet (2003) 362:132-3. doi:10.1016/S0140-6736(03)13897-4

53. Cakic V. Smart drugs for cognitive enhancement: ethical and pragmatic considerations in the era of cosmetic neurology. J Med Ethics (2009) 35:611-5. doi:10.1136/jme.2009.030882

54. Banjo OC, Nadler R, Reiner PB. Physician attitudes towards pharmacological cognitive enhancement: safety concerns are paramount. PLoS One (2010) 5:e14322. doi:10.1371/journal.pone. 0014322

55. Franke AG, Lieb K, Hildt E. What users think about the differences between caffeine and illicit/prescription stimulants for cognitive enhancement. PLoS One (2012) 7:e40047. doi:10.1371/journal.pone.0040047

56. Partridge BJ, Bell SK, Lucke JC, Yeates S, Hall WD. Smart drugs "as common as coffee": media hype about neuroenhancement. PLoS One (2011) 6:e28416. doi:10.1371/journal.pone.0028416

57. Vanderschuren LJ, Trezza V, Griffioen-Roose S, Schiepers OJ, Van Leeuwen N, De Vries TJ, et al. Methylphenidate disrupts social play behavior in adolescent rats. Neuropsychopharmacology (2008) 33:2946-56. doi:10.1038/ npp. 2008.10

58. Griggs R, Weir C, Wayman W, Koeltzow TE. Intermittent methylphenidate during adolescent development produces locomotor hyperactivity and an enhanced response to cocaine compared to continuous treatment in rats. Pharmacol Biochem Behav (2010) 96:166-74. doi:10.1016/j.pbb.2010. 04.026

59. Rowan JD, McCarty MK, Kundey SM, Osburn CD, Renaud SM, Kelley BM, et al. Adolescent exposure to methylphenidate impairs serial pattern learning in the serial multiple choice (SMC) task in adult rats. Neurotoxicol Teratol (2015) 51:21-6. doi:10.1016/j.ntt.2015.07.007 
60. Izquierdo A, Pozos H, Torre Ade L, DeShields S, Cevallos J, Rodriguez J, et al. Sex differences, learning flexibility, and striatal dopamine D1 and D2 following adolescent drug exposure in rats. Behav Brain Res (2016) 308: 104-14. doi:10.1016/j.bbr.2016.04.028

61. Bolanos CA, Barrot M, Berton O, Wallace-BlackD, Nestler EJ. Methylphenidate treatment during pre- and periadolescence alters behavioral responses to emotional stimuli at adulthood. Biol Psychiatry (2003) 54:1317-29. doi:10.1016/ S0006-3223(03)00570-5

62. Britton GB, Segan AT, Sejour J, Mancebo SE. Early exposure to methylphenidate increases fear responses in an aversive context in adult rats. Dev Psychobiol (2007) 49:265-75. doi:10.1002/dev.20213

63. Gomes KM, Souza RP, Valvassori SS, Reus GZ, Inacio CG, Martins MR, et al. Chronic methylphenidate-effects over circadian cycle of young and adult rats submitted to open-field and object recognition tests. Curr Neurovasc Res (2009) 6:259-66. doi:10.2174/156720209789630357

64. Algahim MF, Yang PB, Burau KD, Swann AC, Dafny N. Repetitive ritalin treatment modulates the diurnal activity pattern of young SD male rats. Cent Nerv Syst Agents Med Chem (2010) 10:247-57. doi:10.2174/1871524911006030247

65. Marco EM, Adriani W, Ruocco LA, Canese R, Sadile AG, Laviola G. Neurobehavioral adaptations to methylphenidate: the issue of early adolescent exposure. Neurosci Biobehav Rev (2011) 35:1722-39. doi:10.1016/j.neubiorev. 2011.02.011

66. Urban KR, Gao WJ, Waterhouse BW. Distinct age-dependent effects of methylphenidate on developing and adult prefrontal neurons. Biol Psychiatry (2012) 72:880-8. doi:10.1016/j.biopsych.2012.04.018

67. Urban KR, Li YC, Gao WJ. Treatment with a clinically-relevant dose of methylphenidate alters NMDA receptor composition and synaptic plasticity in the juvenile rat prefrontal cortex. Neurobiol Learn Mem (2012) 101:65-74. doi:10.1016/j.nlm.2013.01.004

68. Li YC, Xi D, Roman J, Huang YQ, Gao WJ. Activation of glycogen synthase kinase- 3 beta is required for hyperdopamine and D2 receptor-mediated inhibition of synaptic NMDA receptor function in the rat prefrontal cortex. J Neurosci (2009) 29:15551-63. doi:10.1523/JNEUROSCI.3336-09.2009

69. Escalante OD, Ellinwood EH Jr. Central nervous system cytopathological changes in cats with chronic methedrine intoxication. Brain Res (1970) 21:151-5. doi:10.1016/0006-8993(70)90033-8

70. Ryan LJ, Linder JC, Martone ME, Groves PM. Histological and ultrastructural evidence that $\mathrm{D}$-amphetamine causes degeneration in neostriatum and frontal cortex of rats. Brain Res (1990) 518:67-77. doi:10.1016/0006-8993(90) 90955-B

71. Parsons LH, Smith AD, Justice JB Jr. Basal extracellular dopamine is decreased in the rat nucleus accumbens during abstinence from chronic cocaine. Synapse (1991) 9:60-5. doi:10.1002/syn.890090109

72. Ellison G. Continuous amphetamine and cocaine have similar neurotoxic effects in lateral habenular nucleus and fasciculus retroflexus. Brain Res (1992) 598:353-6. doi:10.1016/0006-8993(92)90207-P

73. Seiden LS, Sabol KE. Methamphetamine and methylenedioxymethamphetamine neurotoxicity: possible mechanisms of cell destruction. NIDA Res Monogr (1996) 163:251-76.

74. Robinson TE, Kolb B. Structural plasticity associated with exposure to drugs of abuse. Neuropharmacology (2004) 47(Suppl 1):33-46. doi:10.1016/ j.neuropharm.2004.06.025

75. Connell PH. The amphetamines-II. Med World (1962) 96:106-11.

76. KalantOJ. The Amphetamines: ToxicityandAddiction.Springfield,IL:Charles C. Thomas (1966).

77. Ellinwood EH Jr. Behavioral and EEG changes in the amphetamine model of psychosis. Adv Biochem Psychopharmacol (1974) 12:281-97.

78. Mathews IZ, Kelly H, McCormick CM. Low doses of amphetamine lead to immediate and lasting locomotor sensitization in adolescent, not adult, male rats. Pharmacol Biochem Behav (2010) 97:640-6. doi:10.1016/ j.pbb.2010.11.011

79. Sesack SR, Hawrylak VA, Matus C, Guido MA, Levey AI. Dopamine axon varicosities in the prelimbic division of the rat prefrontal cortex exhibit sparse immunoreactivity for the dopamine transporter. J Neurosci (1998) 18:2697-708.

80. Giros B, Wang YM, Suter S, McLeskey SB, Pifl C, Caron MG. Delineation of discrete domains for substrate, cocaine, and tricyclic antidepressant interactions using chimeric dopamine-norepinephrine transporters. J Biol Chem (1994) 269:15985-8.
81. Gu H, Wall SC, Rudnick G. Stable expression of biogenic amine transporters reveals differences in inhibitor sensitivity, kinetics, and ion dependence. J Biol Chem (1994) 269:7124-30.

82. Schmeichel BE, Zemlan FP, Berridge CW. A selective dopamine reuptake inhibitor improves prefrontal cortex-dependent cognitive function: potential relevance to attention deficit hyperactivity disorder. Neuropharmacology (2013) 64:321-8. doi:10.1016/j.neuropharm.2012.07.005

83. Banaschewski T, Roessner V, Dittmann RW, Santosh PJ, Rothenberger A. Non-stimulant medications in the treatment of ADHD. Eur Child Adolesc Psychiatry (2004) 13(Suppl 1):I102-16. doi:10.1007/s00787-004-1010-x

84. Christman AK, Fermo JD, Markowitz JS. Atomoxetine, a novel treatment for attention-deficit-hyperactivity disorder. Pharmacotherapy (2004) 24:1020-36. doi:10.1592/phco.24.11.1020.36146

85. Upadhyaya HP, Desaiah D, Schuh KJ, Bymaster FP, Kallman MJ, Clarke DO, et al. A review of the abuse potential assessment of atomoxetine: a nonstimulant medication for attention-deficit/hyperactivity disorder. Psychopharmacology (Berl) (2013) 226:189-200. doi:10.1007/s00213-013-2986-Z

86. Hennissen L, Bakker MJ, Banaschewski T, Carucci S, Coghill D, Danckaerts M, et al. Cardiovascular effects of stimulant and non-stimulant medication for children and adolescents with ADHD: a systematic review and meta-analysis of trials of methylphenidate, amphetamines and atomoxetine. CNS Drugs (2017) 31:199-215. doi:10.1007/s40263-017-0410-7

87. Ding YS, Gallezot JD, Nabulsi N, Lin SF, Ropchan J, Weinzimmer D, et al. Clinical doses of atomoxetine significantly occupy both norepinephrine and serotonin transports: implications on treatment of depression and ADHD. Neuroimage (2014) 1:164-71. doi:10.1016/j.neuroimage.2013.08.001

88. Carboni E, Silvagni A, Vacca C, Di Chiara G. Cumulative effect of norepinephrine and dopamine carrier blockade on extracellular dopamine increase in the nucleus accumbens shell, bed nucleus of stria terminalis and prefrontal cortex. J Neurochem (2006) 96:473-81. doi:10.1111/j.1471-4159.2005.03556.x

89. Urban KR, Li YC, Gao WJ. Treatment with a clinically-relevant dose of methylphenidate alters NMDA receptor composition and synaptic plasticity in the juvenile rat prefrontal cortex. Neurobiol Learn Mem (2013) 101:65-74. doi:10.1016/j.nlm.2013.01.004

90. Arnsten AF, Li BM. Neurobiology of executive functions: catecholamine influences on prefrontal cortical functions. Biol Psychiatry (2005) 57:1377-84. doi:10.1016/j.biopsych.2004.08.019

91. Camp-Bruno JA, Herting RL. Cognitive effects of milacemide and methylphenidate in healthy young adults. Psychopharmacology (Berl) (1994) 115: 46-52. doi:10.1007/BF02244750

92. Elliott R, Sahakian BJ, Matthews K, Bannerjea A, Rimmer J, Robbins TW. Effects of methylphenidate on spatial working memory and planning in healthy young adults. Psychopharmacology (Berl) (1997) 131:196-206. doi:10.1007/ s002130050284

93. Kirschner J, Moll GH, Fietzek UM, Heinrich H, Mall V, Berweck S, et al. Methylphenidate enhances both intracortical inhibition and facilitation in healthyadults. Pharmacopsychiatry (2003)36:79-82.doi:10.1055/s-2003-39049

94. Tomasi D, Volkow ND, Wang GJ, Wang R, Telang F, Caparelli EC, et al. Methylphenidate enhances brain activation and deactivation responses to visual attention and working memory tasks in healthy controls. Neuroimage (2011) 54:3101-10. doi:10.1016/j.neuroimage.2010.10.060

95. Linssen AM, Vuurman EF, Sambeth A, Riedel WJ. Methylphenidate produces selective enhancement of declarative memory consolidation in healthy volunteers. Psychopharmacology (Berl) (2012) 221:611-9. doi:10.1007/ s00213-011-2605-9

96. Caviola L, Faber NS. Pills or push-ups? Effectiveness and public perception of pharmacological and non-pharmacological cognitive enhancement. Front Psychol (2015) 6:1852. doi:10.3389/fpsyg.2015.01852

97. Busardo FP, Kyriakou C, Cipolloni L, Zaami S, Frati P. From clinical application to cognitive enhancement: the example of methylphenidate. Curr Neuropharmacol (2016) 14:17-27. doi:10.2174/1570159X13666150407225902

98. Franke AG, Gransmark P, Agricola A, Schuhle K, Rommel T, Sebastian A, et al. Methylphenidate, modafinil, and caffeine for cognitive enhancement in chess: a double-blind, randomised controlled trial. Eur Neuropsychopharmacol (2017). doi:10.1016/j.euroneuro.2017.01.006

99. Andersen SL, Thompson AT, Rutstein M, Hostetter JC, Teicher MH. Dopamine receptor pruning in prefrontal cortex during the periadolescent period in rats. Synapse (2000) 37:167-9. doi:10.1002/1098-2396(200008)37:2<167:: AID-SYN11>3.0.CO;2-B 
100. Boog M, Hoppener P, BJ VDW, Goudriaan AE, Boog MC, Franken IH. Cognitive inflexibility in gamblers is primarily present in reward-related decision making. Front Hum Neurosci (2014) 8:569. doi:10.3389/fnhum. 2014.00569

101. Dong G, Lin X, Zhou H, Lu Q. Cognitive flexibility in internet addicts: fMRI evidence from difficult-to-easy and easy-to-difficult switching situations. Addict Behav (2014) 39:677-83. doi:10.1016/j.addbeh.2013.11.028

102. Istin $\mathrm{M}$, Thiriet $\mathrm{N}$, Solinas $\mathrm{M}$. Behavioral flexibility predicts increased ability to resist excessive methamphetamine self-administration. Addict Biol (2017) 22:958-66. doi:10.1111/adb.12384
Conflict of Interest Statement: The authors declare that the research was conducted in the absence of any commercial or financial relationships that could be construed as a potential conflict of interest.

Copyright $\odot 2017$ Urban and Gao. This is an open-access article distributed under the terms of the Creative Commons Attribution License (CC BY). The use, distribution or reproduction in other forums is permitted, provided the original author(s) or licensor are credited and that the original publication in this journal is cited, in accordance with accepted academic practice. No use, distribution or reproduction is permitted which does not comply with these terms. 